\title{
Very short-term forecast of near-coastal flow using scanning lidars
}

\author{
Laura Valldecabres ${ }^{1}$, Alfredo Peña ${ }^{2}$, Michael Courtney ${ }^{2}$, Lueder von Bremen ${ }^{1}$, and Martin Kühn ${ }^{1}$ \\ ${ }^{1}$ ForWind - University of Oldenburg, Institute of Physics, \\ Küpkersweg 70, 26129 Oldenburg, Germany \\ ${ }^{2}$ DTU Wind Energy, Risø Campus, Technical University of Denmark, \\ Frederiksborvej 399, 4000 Roskilde, Denmark
}

Correspondence: Laura Valldecabres (laura.valldecabres@forwind.de)

Received: 26 October 2017 - Discussion started: 18 December 2017

Revised: 5 March 2018 - Accepted: 29 April 2018 - Published: 31 May 2018

\begin{abstract}
Wind measurements can reduce the uncertainty in the prediction of wind energy production. Today, commercially available scanning lidars can scan the atmosphere up to several kilometres. Here, we use lidar measurements to forecast near-coastal winds with lead times of $5 \mathrm{~min}$. Using Taylor's frozen turbulence hypothesis together with local topographic corrections, we demonstrate that wind speeds at a downstream position can be forecast by using measurements from a scanning lidar performed upstream in a very short-term horizon. The study covers 10 periods characterised by neutral and stable atmospheric conditions. Our methodology shows smaller forecasting errors than those of the persistence method and the autoregressive integrated moving average (ARIMA) model. We discuss the applicability of this forecasting technique with regards to the characteristics of the lidar trajectories, the site-specific conditions and the atmospheric stability.
\end{abstract}

\section{Introduction}

Wind energy is growing worldwide as a major source of green energy. In 2017 Denmark produced a record $43.4 \%$ of the country's electricity with wind energy (Danish Wind Industry Association, DWIA). As the share of variable energy into the grid grows, more effort is required to increase the flexibility of power systems in such a way that they can guarantee the grid stability (Holttinen et al., 2016) and the reliability of energy supply (Ibanez and Milligan, 2012). For power systems with a high penetration of intermittent renewable energy, one of the most important sources of imbalances is wind energy forecast errors (Gonzalez-Aparicio and Zucker, 2015). On short timescales, transmission system operators maintain the balance between electricity production and demand, activating balancing reserves. Due to their high flexibility to respond to short-term changes in power, balancing reserves mostly come from conventional power plants, which reduces the environmental and economic benefits of wind energy. In countries like Belgium, the Netherlands and Germany, the electricity market partic- ipants can submit their intraday bids until 5 min before delivery (EPEXSPOT, 2017). With potentially shorter gate closure times wind power suppliers can better match production with demand, thus minimising the costs arising from the deviation between scheduled wind energy production and real generation (Wang et al., 2016).

In very short-term horizons, i.e. from minutes to $1 \mathrm{~h}$, wind forecasts are normally based on statistical models. They are built on relationships developed among historical measurements, assuming that these relationships are also applicable in the future. Examples of statistical methods used to predict wind speed and power can be found in Hill et al. (2012) for the autoregressive (AR) model, Torres et al. (2005) for the autoregressive moving average (ARMA) model and Kavasseri and Seetharaman (2009) for the autoregressive integrated moving average (ARIMA) model. Torres et al. (2005) applied the ARMA model to predict hourly average wind speeds at five weather stations in Navarre, Spain, during different times of the year, with a forecasting horizon from 1 to $10 \mathrm{~h}$. They showed smaller errors for ARMA models 
compared to those of the persistence method. The classical persistence model predicts that the future value will be the same as the current value. This is the simplest version of the ARMA model and is often considered to be a benchmark for other forecasting techniques (Giebel et al., 2011).

Another forecasting technique is the spatial correlation method, which uses the wind speed at upstream neighbouring points to predict the wind speed at a downstream location. The first spatial correlation models were developed by Schlueter et al. (1986). They predicted meteorological events based on cross-correlation curves of wind speeds at two sites using a constant delay method. Alexiadis et al. (1998) tested this method in the Greek islands of Syros and Paros in a time horizon of $10 \mathrm{~min}$ to some hours. Although there was a high correlation between the two sites in terms of fluctuations, the errors were higher than those of the persistence method both in magnitude and phase. They later proposed a spatial correlation predictor method, which uses linear relations to correct magnitude and phase errors.

Recently, various techniques based on artificial neural networks, which are trained with large historic data from the location, were developed (Cadenas and Rivera, 2009; Monfared et al., 2009; Li and Shi, 2010). Damousis et al. (2004) implemented a wind forecasting fuzzy model in which wind data from neighbouring meteorological stations at a radius of up to $30 \mathrm{~km}$ were used to predict wind speed and power in horizons of $30 \mathrm{~min}$ to $2 \mathrm{~h}$. The model results showed significant improvement in the forecasting error of wind speed and power compared to those of the persistence model, especially when applied on flat terrain.

Wind forecasting techniques can combine physical and statistical approaches. As an example, Larson and Westrick (2006) used off-site observations in the vicinity of a wind farm in north-eastern Oregon as input variables in different forecast models such as neural networks and support vector machines. They showed that the integration of real-time offsite observations significantly improves the forecasting accuracy of those algorithms.

Today, remote-sensing systems like lidars are intensively being deployed for wind resource assessment (Wharton et al., 2015), turbine control (Mikkelsen et al., 2013) and turbulence characterisation (Peña et al., 2017). Lidars are proven to be relevant for very short-term forecasting (Frehlich, 2013) as the current generation of commercially available units can scan in various atmospheric conditions up to $30 \mathrm{~km}$. As an example, a $4 \mathrm{~m} \mathrm{~s}^{-1}$ wind speed could be observed by a lidar located in a wind farm $3.6 \mathrm{~km}$ upstream and $15 \mathrm{~min}$ ahead, thus predicting the start of power generation. Remotesensing systems could also be used to better schedule maintenance of offshore wind farms (Barthelmie et al., 2008), e.g. during periods of low wind speeds.

With our study we want to (i) experimentally investigate how lidar observations can be used to forecast wind speeds in a very short-term horizon assuming Taylor's frozen turbulence hypothesis (Taylor, 1938) and (ii) test if with the

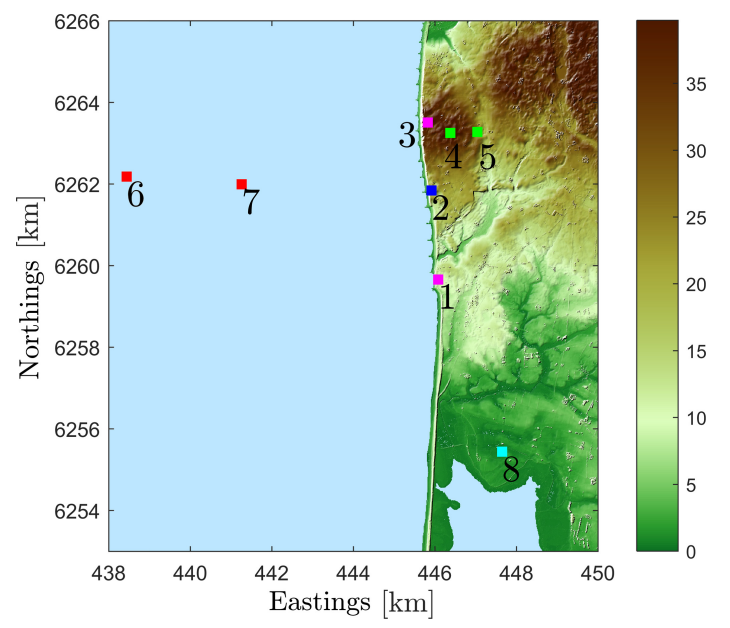

Figure 1. Map of the area of the RUNE campaign indicating the positions of the dual-set-up lidars ( 1 and 3), the PPI lidar (2), the profiling lidars $(2,4,5,6(7))$, the met mast (8) and the wave buoy (9) located $150 \mathrm{~m}$ away from position 6 . The colour bar shows the height above mean sea level in metres.

use of lidar measurements we can predict wind speeds better than with the benchmarks ARIMA and the persistence model. For this, we use lidar observations up to $6 \mathrm{~km}$ in a near-coastal area in Denmark as an input for an advectionbased wind speed forecast technique. The observations are characterised by rather high wind speeds, which limit the forecasting horizon to $5 \mathrm{~min}$. The lidar measurements are described in Sect. 2.1. An insight into the wind conditions is given in Sect. 2.2. The location of the lidars in the nearcoastal area made it necessary to consider the topographic local conditions, which are modelled in Sect. 3. Section 4 gives a detailed description of the methodology used to forecast wind speeds using the lidar measurements. In Sect. 5 results are presented through comparisons between the accuracy of forecasting wind speeds based on the advection models and with persistence and ARIMA models. We discuss the suitability of using long-range lidars for very short-term forecasting and provide main conclusions in Sect. 6.

\section{Wind data analysis}

Our study is based on measurements performed during the Reducing Uncertainty of Near-shore wind resource Estimates (RUNE) campaign (Simon and Courtney, 2016; Floors et al., 2016b). The experiment was conducted at the western coast of Denmark, north of the area of Høvsøre (see Fig. 1) and close to one of the Technical University of Denmark's wind turbine test stations. A comprehensive analysis of the wind conditions at Høvsøre during a 10-year period from the test station's meteorological mast, located $1.7 \mathrm{~km}$ east of the North Sea (see Fig. 1, position 8), is presented in Peña et al. (2016). A pronounced cliff at the coastline (see Fig. 2) is 


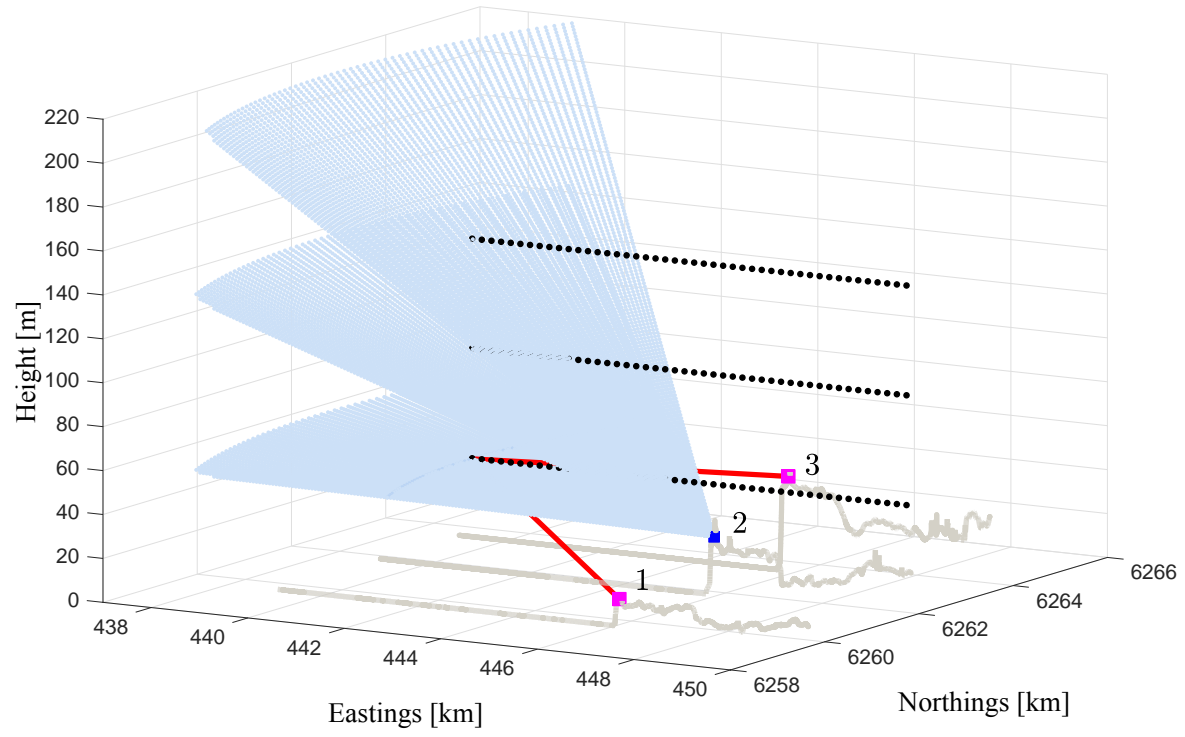

Figure 2. Scanning trajectories of the dual-set-up (black dots) and the PPI (light blue points) scenarios. The red lines show two laser beams from the dual-set-up lidars (magenta boxes) focusing at position 7 (see Fig. 1). The grey lines indicate the terrain height above sea level.

the main feature of the terrain, which is mainly covered with grass and crops.

During the RUNE campaign, which took place during November 2015 to February 2016, profiling and scanning lidars were deployed to measure near-coastal wind conditions (see Fig. 1). Four short-range (positions 2, 4, 5 and 6 (later 7)) and one long-range (position 2) profiling lidar measured the wind profile. One scanning lidar (position 2) was operated in plan position indicator (PPI) mode, also known as the "sector-scan" scenario. Simultaneously, two more scanning lidars (positions 1 and 3) were configured in a dual trajectory to match at positions along three horizontal virtual lines. In what follows we will refer to them as the dual set-up. In Fig. 2 the positions of the dual set-up and the PPI are shown. The PPI and the dual-set-up trajectories were designed so that the measurements will intersect at $5000 \mathrm{~m}$ offshore at 50, 100 and 150 ma.m.s.l. Further, a directional wave buoy (position 9) was deployed to measure waves, currents and sea surface temperature (SST) (Floors et al., 2016a; Sanchez and Rørbæk, 2016). Detailed information about the campaign can be found in Floors et al. (2016b). For this work we also use data from the sonic and cup anemometers located at the height of $100 \mathrm{~m}$ on the Høvsøre meteorological mast (position 8). Table 1 summarises the operational availability of all systems used in this study.

\subsection{Lidar data processing and filtering}

\subsubsection{Dual-set-up measurements}

The two lidars measuring in the dual-set-up trajectory acquired 45 line-of-sight (LOS) wind velocities ( $1 \mathrm{~s}$ per LOS) per horizontal virtual line, separated by a distance of $\approx 200 \mathrm{~m}$ between points from $4 \mathrm{~km}$ onshore to $5 \mathrm{~km}$ offshore. Every trajectory, i.e. three horizontal lines at 50, 100 and 150 ma.m.s.l., took $145 \mathrm{~s}$. In total, every position was swept four times every $10 \mathrm{~min}$. Data that did not fulfil a certain distance threshold between the two lidar measurement positions were discarded. Regarding data quality, a carrier-to-noise ratio (CNR) threshold of $-26.50 \mathrm{~dB}$ was set. For every $10 \mathrm{~min}$ period and each point, the horizontal wind speed components were reconstructed as described in Simon and Courtney (2016). Due to the low availability in the reconstruction at positions further away from the coast (Floors et al., 2016b), we only consider data up to $2950 \mathrm{~m}$. Observations close to the lidar systems (range $<500 \mathrm{~m}$ ) were also discarded since here the angle between the beams approaches $180^{\circ}$ and, consequently, the uncertainty of the reconstructed speed becomes very high (Stawiarski et al., 2013).

\subsubsection{PPI measurements}

The lidar at position 2 measured 45 different azimuthal positions over three different elevations, performing a $60^{\circ}$ sweep every $45 \mathrm{~s}$, scanning in the westerly direction $\left(240-300^{\circ}\right)$. The elevation angles were $0.27,0.84$ and $1.41^{\circ}$. The full trajectory lasted $145 \mathrm{~s}$ accounting for the $10 \mathrm{~s}$ that the scan needed to return to its initial position. For every azimuthal position, 156 range gates from 100 to $8150 \mathrm{~m}$ (separated every $50 \mathrm{~m}$ ) were measured. The horizontal wind speed was reconstructed for every single scan and range gate, resulting in a horizontal wind speed at each range gate and elevation every $145 \mathrm{~s}$; thus four measurements were performed within a $10 \mathrm{~min}$ period. Due to the low availability of data at long ranges when using a filtering threshold (Floors et al., 2016b), 
Table 1. Measurement periods, positions and operational availability for all of the systems used in the analysis.

\begin{tabular}{|c|c|c|c|c|c|c|c|}
\hline Position & System & $\begin{array}{l}\text { Easting }(\mathrm{m}) / \\
\text { northing }(\mathrm{m})\end{array}$ & $\begin{array}{r}\text { Height } \\
\text { a.m.s.l. }(\mathrm{m})\end{array}$ & Measurement & $\begin{array}{l}\text { Start and end } \\
\text { day/month }\end{array}$ & Data (h) & $\begin{array}{r}\text { Operational } \\
\text { availability }(\%)\end{array}$ \\
\hline 1 & Scanning lidar & $\begin{array}{r}446080.03 \\
6259660.30\end{array}$ & 12.36 & Dual set-up & 03/12-17/02 & 1250.4 & 70.62 \\
\hline 2 & Scanning lidar & $\begin{array}{r}445915.64 \\
6261837.49\end{array}$ & 26.38 & PPI & 26/11-17/02 & 1575.2 & 79.38 \\
\hline 8 & Høvsøre mast & $\begin{array}{r}447642.00 \\
6255431.00\end{array}$ & 0.32 & $\begin{array}{l}\text { Sonic }(100 \mathrm{~m}) \\
\text { Wind vane }(100 \mathrm{~m}) \\
\text { Wind cup }(100 \mathrm{~m}) \\
\text { Temperature sensor }(100 \mathrm{~m})\end{array}$ & $\begin{array}{l}01 / 11-29 / 02 \\
01 / 11-29 / 02 \\
01 / 11-29 / 02 \\
01 / 11-29 / 02\end{array}$ & $\begin{array}{l}2740.7 \\
2756.3 \\
2757.0 \\
2168.0\end{array}$ & $\begin{array}{l}96.51 \\
97.07 \\
97.09 \\
76.37\end{array}$ \\
\hline
\end{tabular}

(a)

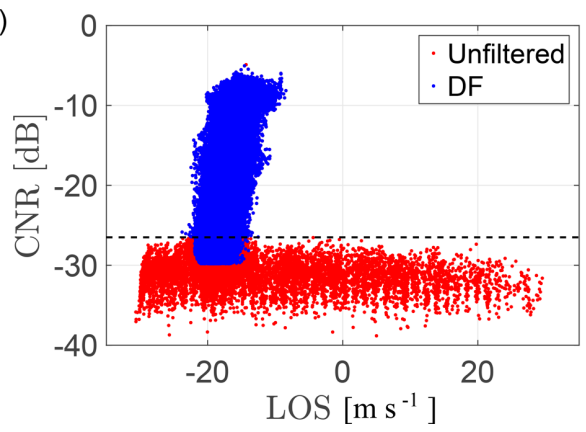

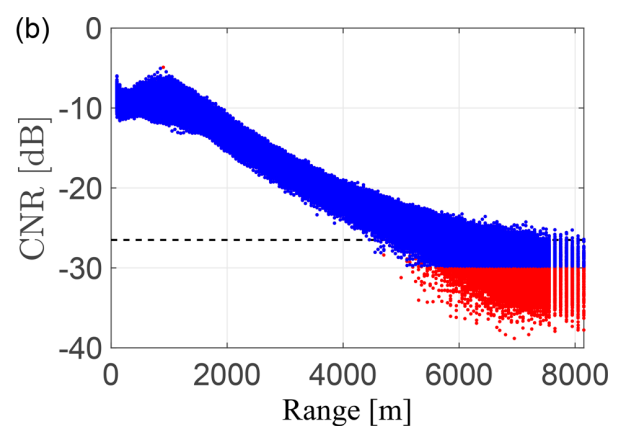

Figure 3. LOS-CNR plot (a) and range-CNR plot (b) for the original lidar data (red and blue colours) and the data filtered with the dynamic filter (DF) (blue) for a 10 min measurement period. The dashed line represents the threshold line of $-26.5 \mathrm{~dB}$ used in the conventional filter.

a dynamic filter is applied to "rescue" LOSs as shown in Beck and Kühn (2017). For every $10 \mathrm{~min}$ period, the probability density function of the data is calculated using a 2-D histogram. Measurement points fulfilling a lower threshold of $-26.5 \mathrm{~dB}$ and an upper threshold of $-5 \mathrm{~dB}$ are considered. LOSs below the CNR lower threshold are still considered, if their local probability density lies within 1 standard deviation of the mean probability density. LOS measurements below $-30 \mathrm{~dB}$ are always discarded. A final visual checking is applied to remove outliers. In Fig. 3, a comparison of the two filtering techniques is presented. As shown in the range-CNR plot, for these data the use of a dynamic filter extends the range of measurements from 4.6 to $6 \mathrm{~km}$. The availability of LOS measurements for the two filtering techniques is shown in Fig. 4. For a distance of $6000 \mathrm{~m}$ from the coast, the use of the dynamic filter increases the data availability from 33.65 to $73.29 \%$.

A comparison of the wind speeds observed by the dual setup and the PPI at their matching positions $5 \mathrm{~km}$ offshore can be found in Floors et al. (2016b). In general, the 10 min mean reconstructed wind speeds from the PPI show a good agree- ment with the dual-set-up ones, especially close to the coast. At further distances from the coast, higher mean differences are found. These are related to the different size of the measuring volume of the lidars, the inherent temporal and spatial variability in the wind speed, and the distinct reconstruction methods. While the reconstruction in the PPI is performed with a sinusoidal fit of $60^{\circ}$, the dual set-up uses two LOSs from the two lidars at a similar position in space. The uncertainties arising from the nature of the two systems are not clearly addressed. For the PPI, we need to assume horizontal flow homogeneity. At distant ranges wider areas are covered, and there is a higher uncertainty in the reconstruction. In addition, the PPI trajectories are not horizontal. For the dual set-up, we do not assume horizontal flow homogeneity, but the measurement ranges are longer than in the PPI and, consequently, the uncertainty in the sensing height will be higher. 


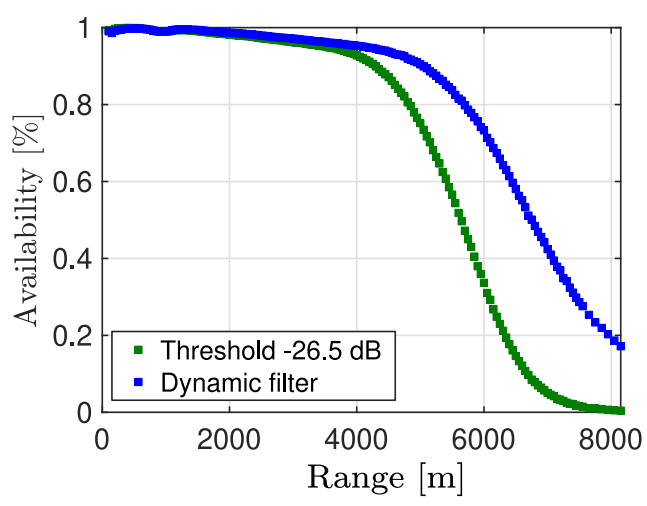

Figure 4. Availability of LOS measurements as a function of the range with a CNR threshold of $-26.5 \mathrm{~dB}$ (green) and a dynamic filter (blue).

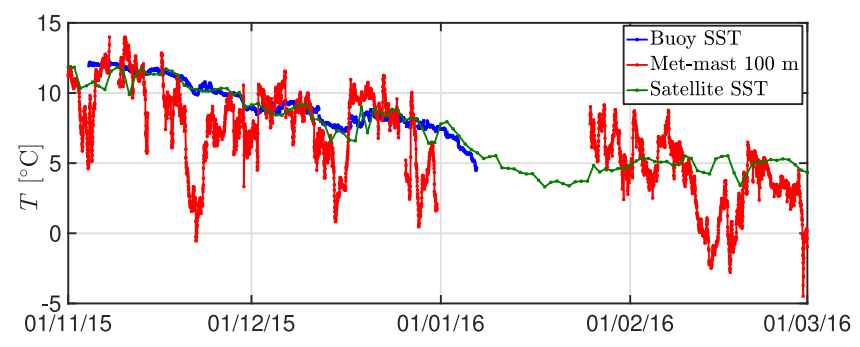

Figure 5. Time series of temperatures measured by the satellites, mast and buoy.

\subsection{Observed wind conditions}

The campaign was characterised by strong south-westerly winds. For subsequent analysis we want to estimate the atmospheric stability conditions during the campaign. Since there are no measurements of this type in the offshore area, we estimate the offshore stability based on sonic anemometer measurements from the Høvsøre met mast. We select the highest sonic anemometer, at $100 \mathrm{~m}$, since this is less influenced by the land effects and by internal boundary layers growing during westerly winds. The analysis based on the derived Obukhov length $L$ at the $100 \mathrm{~m}$ sonic anemometer reveals that during the winter months, there were mostly stable conditions $(56.5 \%)$ followed by neutral $(27.8 \%)$ and unstable conditions $(15.7 \%)$. Three classes are used for the stability classification, with $z / L<-0.1$ for unstable, $-0.1 \leq$ $z / L \leq 0.1$ for neutral and $z / L>0.1$ for stable conditions. To test if we can estimate the offshore stability based on the onshore measurements, we conduct a comparison of the gradient of the potential temperature between the sea and the air, and the $L$ estimated from the sonic measurements. The directional wave buoy located at position 9 measured the SST every $30 \mathrm{~min}$. Due to a major failure in the buoy system, only measurements until the beginning of January 2016 were recorded (see Table 1 for more details). A comparison with the SST derived from satellite images is shown in

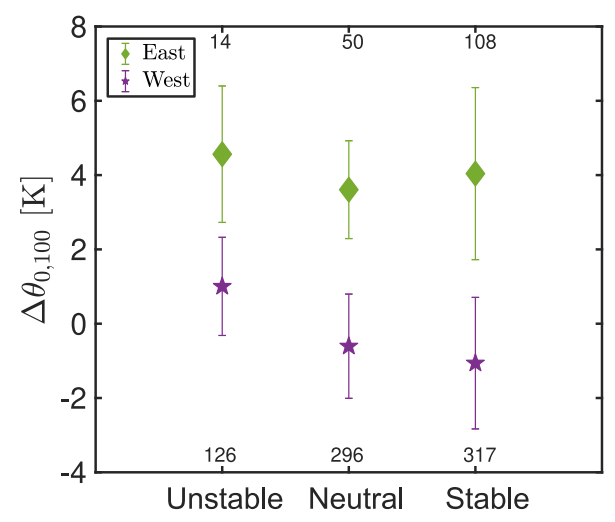

Figure 6. Potential temperature gradient between the SST and the air temperature at $100 \mathrm{~m}$ for three stability classes. The diamond (easterlies) and the star (westerlies) represent the mean. The error bars represent the standard deviation within each stability class. Numbers above and below the error bars refer to the number of periods used for the analysis.

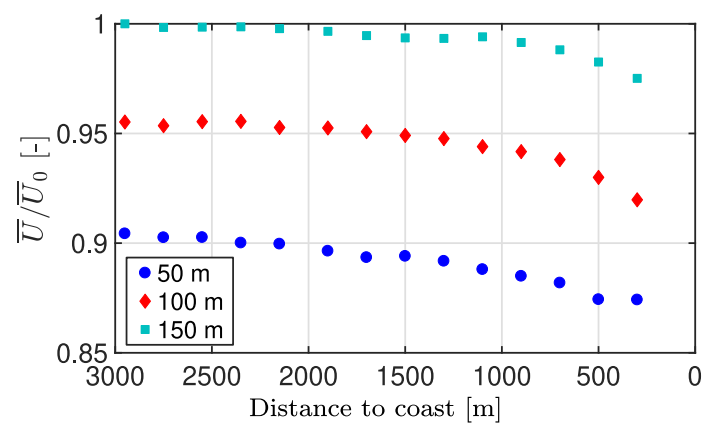

Figure 7. Normalised coastal wind gradient along the dual-set-up transect of reconstructed wind speed measurements for westerly winds at 50, 100 and $150 \mathrm{ma}$ a.m.s.l. for neutral periods. $U_{0}$ is the mean wind speed at $2950 \mathrm{~m}$ to the coast at $150 \mathrm{~m}$ height.

Fig. 5. The SST was computed from night-time observations from NOAA, AVHRR, Metop AVHRR, Terra MODIS, Aqua MODIS, Aqua AMSR-E, Envisat AATSR and MSG SEVIRI satellites based on the interpolation method described in Høyer and She (2007). The spatial resolution of the satellite SST is $0.02^{\circ} \times 0.02^{\circ}$ and its temporal resolution is $24 \mathrm{~h}$. Figure 5 shows that the differences between both SSTs are small and both SSTs do not vary as much as the air temperature measured by the temperature sensor at $100 \mathrm{~m}$ on the mast.

To conduct the comparison with the stability from the met mast, we calculate the potential temperature gradient between the sea surface (buoy) and the air (met mast $100 \mathrm{~m}$ ) for every $30 \mathrm{~min}$ period, first clustering the data according to the wind direction and second using the $30 \mathrm{~min}$ averaged $L$ (sonic at $100 \mathrm{~m}$ ). Only westerly and easterly sectors were analysed. The sign of the mean gradient of the potential temperature between the sea surface and the air for westerly 

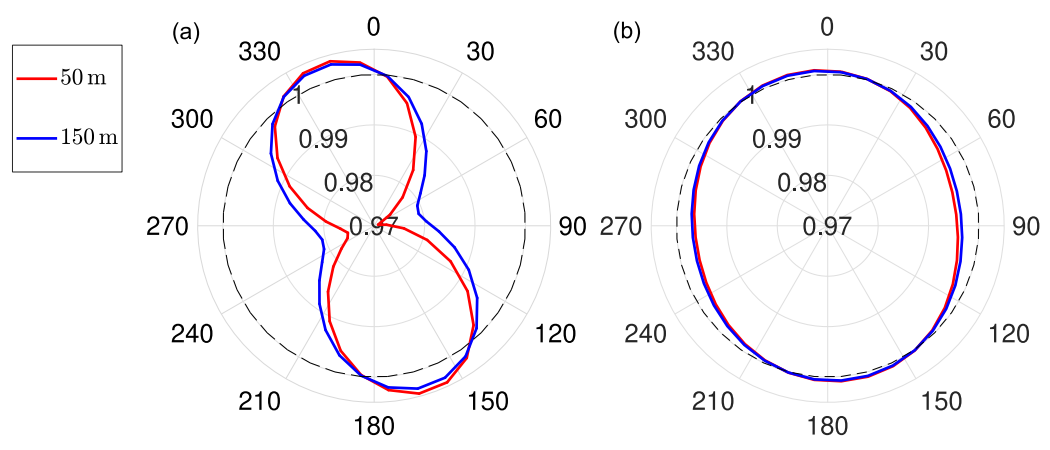

Figure 8. Directional orography effects $O(x, z, \mathrm{dd})$ at $x=500 \mathrm{~m}$ (a) and $x=2950 \mathrm{~m}$ (b) from the coast at two heights above mean sea level.

winds (see Fig. 6) is in agreement with the stability from the sonic anemometer at $100 \mathrm{~m}$. For easterly winds there is no such correspondence, as expected. For westerly winds we will assume that the stability measured by the onshore metmast at $100 \mathrm{~m}$ is a good indicator of the stability of the offshore area. Our further analysis refers to data from westerly winds during neutral and stable conditions.

\subsubsection{Coastal gradient for westerly winds}

We analyse the influence of the land on the wind speed in the near-coastal area by using the dual-set-up lidar observations at offshore positions. Due to the reduced availability of measurements at distant positions, we look at 10 min periods up to $3 \mathrm{~km}$ offshore. Figure 7 shows the ensemble average wind speed of all $10 \mathrm{~min}$ mean wind speeds reconstructed from the dual-set-up observations at 50,100 and $150 \mathrm{~m}$ a.m.s.l. for periods with neutral stratification. For all heights, the flow slows down when approaching the coast.

\section{Modelling coastal effects for wind speed forecasting correction}

We will use the PPI measurements further upstream of the coast to forecast winds at positions close to the coast where we also have PPI measurements. Our forecasting technique is first based on an advection component, in which it is assumed that large turbulent structures are advected with the mean wind. Second we need to vertically extrapolate the wind because the upstream PPI observations are at different heights than those closer to the coast. Last we need corrections due to the influence of the coast; as seen in Fig. 7 the wind has been observed as decreasing as it approaches the coast. Here, we will first show the method used to account for the coastal effects. This is carried out based on the dual-set-up measurements as they are independent of PPI scans and are always performed at the same heights. In this section we will only use dual-set-up measurements up to $3 \mathrm{~km}$ during neutral conditions.
For a homogeneous and stationary flow, the mean wind speed profile is given as

$U(z)=\frac{u_{*}}{\kappa}\left[\ln \left(\frac{z}{z_{0}}\right)-\Psi\left(\frac{z}{L}\right)\right]$,

where $U$ is the mean wind speed, $z$ the height above the ground, $u_{*}$ the friction velocity, $\kappa$ the von Kármán constant $(\approx 0.4)$ and $z_{0}$ the roughness length. To account for stability effects $\Psi$ is included, which depends on the Obukhov length $L$. To model the effects of the orography and roughness on the wind, which depend on the distance to the coast, we assume that the observed (obs) wind speed is

$U_{\text {obs }}(x, z, \mathrm{dd})=U\left(z_{0}(x), z\right) O(x, z, \mathrm{dd})$,

where $O$ is an orography correction that depends on the height $z$, the distance to the coast $x$ and the wind direction dd. Note that we assume that $z_{0}$ varies with the distance to the coast.

\subsection{Orography effects}

The orography effects are estimated using the microscale IBZ model, which is part of the Wind Atlas Analysis and Application Program (WAsP) (Troen and Lundtang Petersen, 1989). The orography correction was determined at each position measured by the dual set-up and for all wind directions using a digital terrain model as an input (Geostyrelsen, 2016). In Fig. 8 the orography corrections for the positions 500 and $2950 \mathrm{~m}$ from the coast and for all wind directions are shown. For westerly winds, at $500 \mathrm{~m}$ from the coast and 50 ma.m.s.l., the wind speed slows down by $\approx 2 \%$. Conversely, for northerly and southerly winds the flow speeds up due to the presence of the cliff. The effects are reduced further from the coast and with increasing height. 

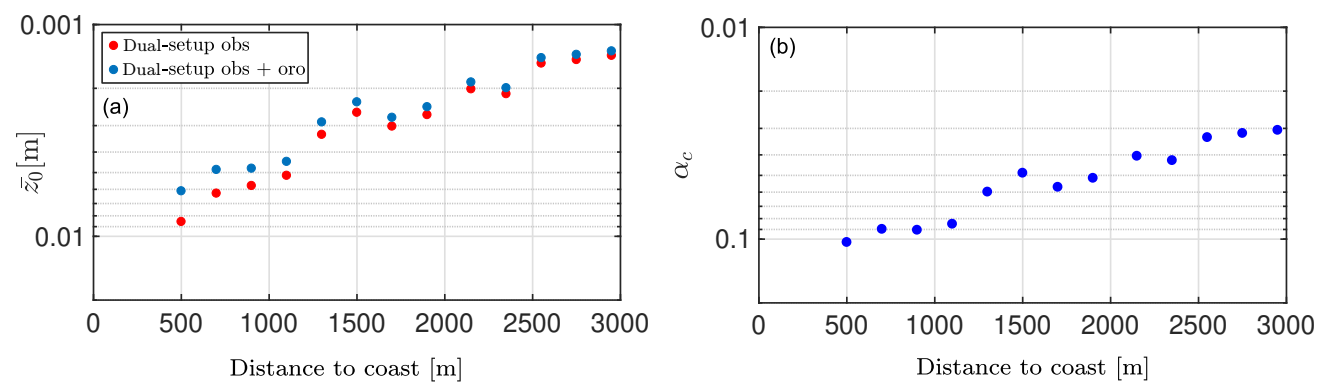

Figure 9. Mean estimated roughness length dependency with distance to the coast for the dual-set-up mean wind profiles after and before applying orography corrections (a). Charnock's parameter dependency with the distance to the coast (b).

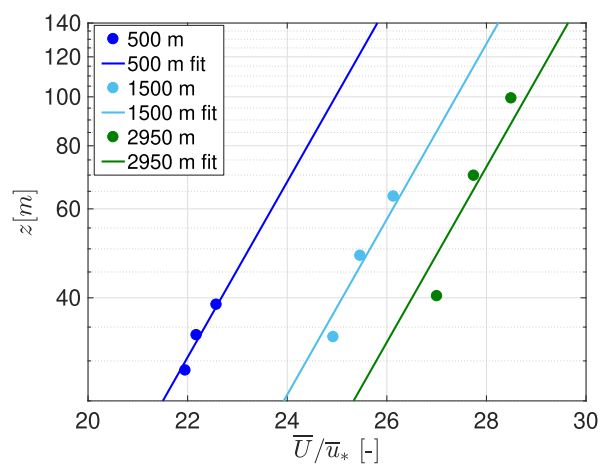

Figure 10. Comparison of the PPI observations with Eqs. (1) and (3) using the $\alpha_{\mathrm{c}}$ dependency on distance to the coast at positions 500,1500 and $2950 \mathrm{~m}$ from the coast.

\subsection{Roughness effects}

We model the influence of the wind on the roughness of the water using the expression of Charnock (1955),

$z_{0}=\alpha_{\mathrm{c}} \frac{u_{*}^{2}}{g}$,

where $\alpha_{\mathrm{c}}$ is the Charnock parameter and $g$ the acceleration due to gravity. For open ocean $\alpha_{\mathrm{c}}=0.011$ has been reported (Smith, 1980) while for a near-coastal area, values between 0.008 and 0.06 can be found (Kraus, 1972). To determine the roughness length dependency with distance to shore, we apply the following strategy. Once the dual-set-up observations at the different range gates are corrected by using the orography corrections, these are used together with Eqs. (1) and (3) to determine both $u_{*}$ and $z_{0}$, and thus $\alpha_{\mathrm{c}}$. Figure $9 \mathrm{~b}$ left shows the dependency of the estimated roughness length with distance to the coast after applying the orography corrections for the neutral cases. The roughness length decreases with distance from the coast. Without orography corrections, the roughness length is slightly higher than the case with corrections close to the coast, as expected. Since the roughness length varies with distance to the coast, so does the Charnock parameter (see Fig. 9b).
We test the estimated Charnock parameter dependency with distance to shore by selecting $10 \mathrm{~min}$ periods during neutral conditions for which both PPI and dual-set-up measurements were performed simultaneously. We fit Eqs. (1) and (3) to the orography-corrected PPI measurements at those positions where we estimated the $\alpha_{\mathrm{c}}$ dependency on distance to the coast with the dual-set-up measurements. The comparison of the estimation of the wind using Eqs. (1) and (3) is shown in Fig. 10. As shown, with increasing distance to the coast, there is an increasing deviation of the fit from Eqs. (1) and (3) to the data, especially at the lowest height observations.

\section{Very short-term wind speed forecast}

As mentioned earlier, we want to forecast wind speeds in a very short-term horizon by assuming Taylor's frozen turbulence hypothesis. For this purpose we consider two positions: the upstream position (1) and the downstream position or forecasting position (2), with the wind blowing from (1) to (2). If at a time $t$ a considerable change in wind speed occurs at position (1), this event will appear at position (2) after some time $\Delta t$. In other words, this event can be foreseen at position (2) with a time ahead $\Delta t$. In our analysis, the downstream position is set to $500 \mathrm{~m}$ from the PPI lidar (position 2) in the westerly direction at $z_{2}=33.76 \mathrm{~m}$, which corresponds to the height of the intermediate PPI elevation scan. Lidar measurements are performed at multiple upstream positions (range gates) from which the forecast can be originated. This can be understood as having multiple virtual met masts over several distances west from the downstream position. To keep a fixed forecast horizon, the upstream position (1) and height $z_{1}$, from which the wind is advected, are determined dynamically at each time stamp using the $5 \mathrm{~min}$ moving-average wind speed $\overline{v_{2}}(t)$ and direction at the downstream position. But because the vector $\overline{v_{2}}(t)$ might not be parallel to the line of virtual met masts, we use the vector projection of the advected distance on the wind direction $\left|\boldsymbol{r}_{12}\right|=\left|\Delta t \overline{\boldsymbol{v}_{2}}(\boldsymbol{t})\right| \cdot \cos (\theta)$, with $\theta$ defined as the angle between the wind direction and $270^{\circ}$. Because high wind speeds were 
observed during the measurement campaign, and the limit for high-quality PPI measurements is $\approx 6 \mathrm{~km}$, we establish a forecast horizon of $5 \mathrm{~min}$. We assume that a change in wind speed, observed $5 \mathrm{~min}$ ahead at the position (1) will propagate and travel the distance $r_{12}$ in the time $\Delta t=5 \mathrm{~min}$.

To incorporate the local effects and the changes in height between the upstream and downstream positions, we consider corrections in the wind speed due to height, roughness and orography. To evaluate the appropriateness of those corrections, we will compare a simple advection model (A), an advection model with height corrections (AH), an advection model with height and roughness length corrections (AHR), and, finally, an advection model with corrections due to height, roughness length change and orography changes (AHRO). We evaluate our forecasting method against the well-known persistence method and an ARIMA model. A summary of the time periods in which the very short-term forecasting method is applied is shown in Table 2. We select periods with mean wind speeds below $18 \mathrm{~m} \mathrm{~s}^{-1}$ and westerly periods, with a minimum duration of $3 \mathrm{~h}$ and with high availability of the data. No unstable periods fulfilled this criteria; therefore we focus here on neutral and stable conditions.

\subsection{Advection model (A)}

For the advection model, $U_{2}(t)$ is estimated as follows.

1. The upstream position (1) at $\left(x_{1}, z_{1}\right)$ from the PPI scan is determined dynamically using the $5 \mathrm{~min}$ movingaverage wind speed at the downstream position and the forecast time horizon $k$ (here $5 \mathrm{~min}$ ). The wind direction from the previous forecasted step is used to calculate the projected distance from which the forecast is originated. For the positions in time and space in which observations at the upstream position are missing, the previous observation is used.

2. The observed wind speed at the upstream position is therefore advected, which means that the forecasted wind speed at the downstream position is considered to be the same as the wind speed in the upstream position, $U_{2, z 2}(t)=U_{1, z 1}(t-k)$.

\subsection{Advection model with height correction (AH)}

This is similar to the A model but the wind speed is extrapolated to match the height of the downstream observation. To do so, the following steps are carried out.

1. Step 1 from model A is conducted.

2. The logarithmic profile in Eq. (1) is fit to three consecutive PPI wind speed observations at position (1). The friction velocity $u_{*, 1}$ and a roughness length $z_{0,1}$ are thus estimated.
3. The roughness length $z_{0,1}$ is used to correct the advected wind speed to the downstream height by using

$U_{2, z 2}(t)=U_{1, z 1}(t-k) \frac{\ln \left(z_{1} / z_{0,1}(t-k)\right)}{\ln \left(z_{2} / z_{0,1}(t-k)\right)}$.

\subsection{Advection model with height and roughness correction (AHR)}

1. Steps 1 and 2 from the AH model are conducted.

2. The friction velocity $u_{*, 1}$ and the roughness length $z_{0,1}$ are used to calculate the geostrophic wind at position (1):

$$
G_{1}(t)=\frac{u_{*, 1}(t)}{\kappa} \sqrt{\left(\ln \left(\frac{u_{*, 1}(t)}{f z_{0,1}}\right)-A\right)^{2}+B^{2}},
$$

where $f$ refers to the Coriolis parameter and $A=1.8$ and $B=4.5$. We assume here that the geostrophic wind at position (2) is the same as at position (1):

$$
G_{2}(t)=G_{1}(t-k) .
$$

3. The geostrophic wind is used to estimate the roughness length $z_{0,2}$ and the friction velocity $u_{*, 2}$. To solve for both parameters in position (1), we assume a fixed Charnock parameter derived from the dual-set-up analysis (see Fig. 9b):

$$
\begin{aligned}
& G_{2}(t)= \frac{u_{*, 2}(t-k)}{\kappa} \\
& \sqrt{\left(\ln \left(\frac{g}{f \alpha_{c, 2} u_{*, 2}(t-k)}\right)-A\right)^{2}+B^{2}}, \\
& z_{0,2}=\alpha_{c, 2} \frac{u_{*, 2}^{2}}{g} .
\end{aligned}
$$

4. The forecasted wind speed is

$U_{2, z 2}(t)=\frac{u_{*, 2}(t-k)}{\kappa} \ln \left(\frac{z_{2}}{z_{0,2}(t-k)}\right)$.

\subsection{Advection model with height, roughness and orography correction (AHRO)}

1. It is assumed that the corrections due to orography at positions further away are negligible.

2. Steps 1-3 from the AHR model are conducted.

3. The orography corrections at the downstream position are applied using the measured wind direction at (1), i.e.

$U_{2, z 2}^{o}(t)=U_{2, z 2}(t) O\left(x_{2}, z_{2}, \mathrm{dd}_{1}\right)$. 
Table 2. Computed statistics of wind speed $(U)$, wind direction (dd), turbulence intensity (TI) and Obukhov length $(L)$ for all evaluated periods, based on the Høvsøre met mast at $100 \mathrm{~m}$.

\begin{tabular}{lllrrrrl}
\hline Period & Starting time & Duration & $\bar{U}\left(\mathrm{~m} \mathrm{~s}^{-1}\right)$ & $\mathrm{dd}\left({ }^{\circ}\right)$ & $\overline{\mathrm{TI}}(\%)$ & $\bar{L}(\mathrm{~m})$ & Stability class \\
\hline 1 & 2 Dec 2015 04:20 & 6h $10 \mathrm{~min}$ & 13.50 & {$[239-260]$} & 4.21 & 268 & Stable \\
2 & 4 Dec 2015 12:50 & 7 h 50 min & 16.56 & {$[229-275]$} & 6.60 & 2217 & Neutral \\
3 & 6 Dec 2015 19:10 & 6 h 20 min & 17.18 & {$[277-288]$} & 7.39 & -1640 & Neutral \\
4 & 9 Dec 2015 10:10 & 3 h 40 min & 12.89 & {$[240-273]$} & 6.36 & -4560 & Neutral \\
5 & 10 Dec 2015 22:50 & 5 h 10 min & 13.37 & {$[242-261]$} & 6.97 & 1383 & Neutral \\
6 & 12 Dec 2015 10:50 & 4 h 50 min & 8.15 & {$[256-304]$} & 5.91 & 166 & Stable \\
7 & 23 Dec 2015 15:50 & 7 h 30 min & 15.89 & {$[238-269]$} & 6.98 & 2178 & Neutral \\
8 & 27 Dec 2015 10:50 & 6h 50 min & 16.34 & {$[248-282]$} & 7.38 & -10122 & Neutral \\
9 & 25 Jan 2016 23:50 & 8 h & 14.28 & {$[225-290]$} & 3.17 & 128 & Stable \\
10 & 31 Jan 2016 23:00 & 5 h 20 min & 7.48 & {$[250-301]$} & 3.80 & 37 & Stable \\
\hline
\end{tabular}
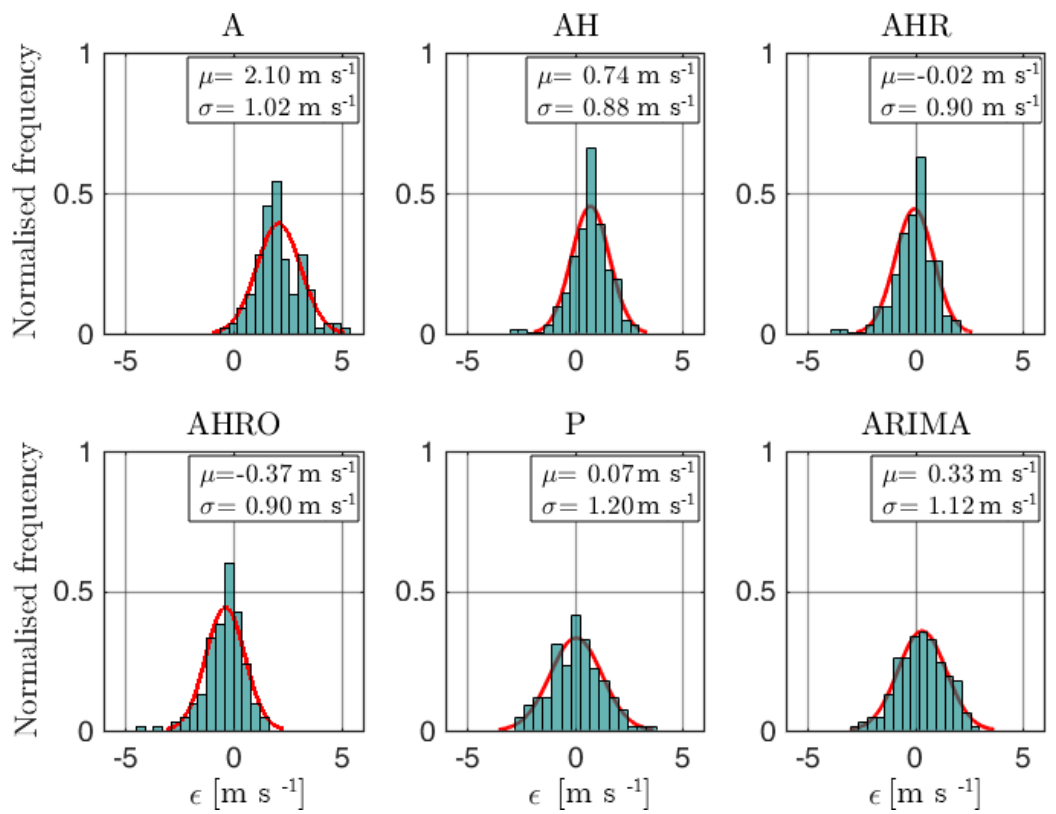

Figure 11. Histogram of the forecast errors $\epsilon$ for period 7 (neutral) for all evaluated models. The red line represents a normal distribution with the same mean $\mu$ and standard deviation $\sigma$ as the distribution of errors.

\subsection{Statistical models}

To evaluate the goodness of the forecasting techniques in Sect. 4, we use the benchmarks persistence and ARIMA.

- ARIMA, denoted as $\operatorname{ARIMA}(p, d, q)$ is a statistical model widely used in very short-term predictions of wind speeds (Kavasseri and Seetharaman, 2009). It uses recent past values (autoregressive, AR) and recent residuals of the forecast (moving average) to predict current values. This model is suitable to analyse non-stationary processes since it uses non-seasonal differences $(d)$ to build the forecasting model. A general equation for the ARIMA model is

$$
\begin{aligned}
U(t+k) & =\sum_{i=1}^{p} \Phi_{i} U(t+k-i)+a(t+k) \\
& -\sum_{j=1}^{q} \Theta_{j} a(t+k-j),
\end{aligned}
$$

where $\Phi_{i}$ is the $i$ th autoregressive parameter, $\Theta_{j}$ is the $j$ th moving-average parameter, $a(t)$ is the error term at time $t, k$ is the forecasting horizon and $U(t)$ is the value of the wind speed observed at the time $t$. Here we build a new ARIMA model for each period. To test the stationarity of the time series, we first look at its autocorrelation function and its partial autocorrelation function. If it has positive autocorrelations out to a high number of lags, we include an order of differentiation $d$. To test if this order is sufficient, we look at the residuals of the 

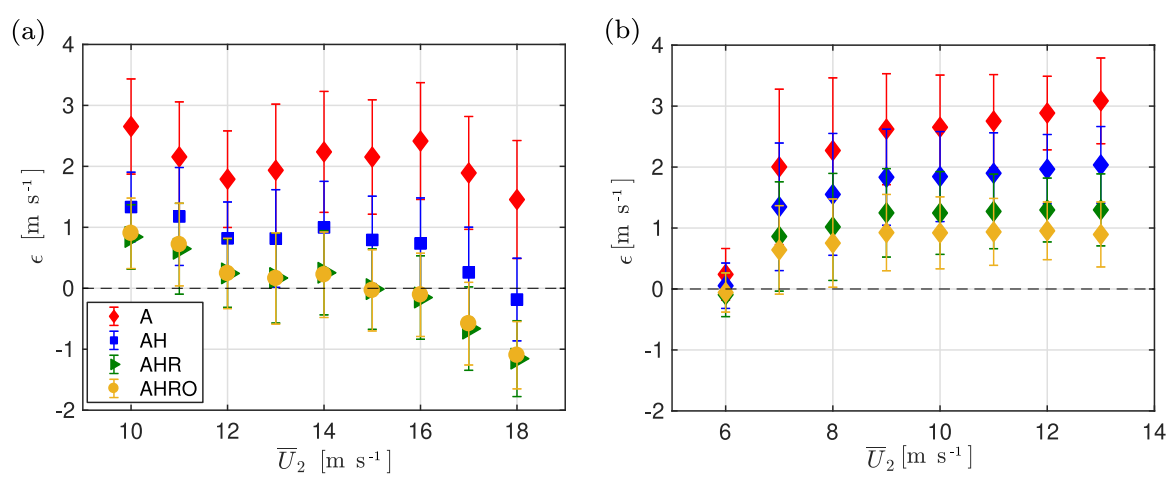

Figure 12. Forecasting error dependency on wind speed for the advection models A, AH, AHR and AHRO for neutral (a) and stable (b) periods.

differentiated time series and perform a unit root test using the Dickey-Fuller test (Dickey and Fuller, 1979). To determine the order $p$ and $q$ of the ARIMA model, we compute the autocorrelation function and the partial autocorrelation function of the stationarized time series, following the method explained in Cadenas and Rivera (2007). The model chosen for every period is the one which minimises the residuals. For every individual set, the previous hour of observations is used to derive the $\mathrm{AR}$ and moving average parameters using the method by Box and Jenkins (1976).

- Persistence is a particular case of the ARIMA model in which $q=0, p=1, d=0$ and the AR coefficient is set to 1 since it assumes that the previous and the current values are highly correlated. Our predicted wind speed is defined as

$$
U(t)=U(t-k) .
$$

\section{Results}

We evaluate the accuracy of the $5 \mathrm{~min}$ forecast of wind speeds based on the described advection techniques and compare it with the results of the statistical methods persistence and ARIMA. To do so, three criteria are employed, namely the root-mean-square error (RMSE), the mean bias error (MBE) and the maximum absolute error (MaxAE). Table 3 includes the RMSE, MBE and MaxAE for all periods stated in Table 2. Minimum values are indicated in bold. The improvements of the advection models over the benchmarks persistence and ARIMA are shown in Table 4. Values corresponding to best performance are indicated in bold.

For neutral conditions (periods 2, 3, 4, 5, 7 and 8), the advection model with corrections performs in general better than the statistical forecasting models. The improvement over persistence using the best calibrated advection model for each period ranges from 21 to $38 \%$ (see Table 4). Compared to the benchmark ARIMA the improvement ranges from 4 to $28 \%$. As an example, the distribution of errors produced by all models for period 7 can be seen in Fig. 11. The forecasting error $\epsilon$ is defined as $\epsilon_{i}=U_{\mathrm{p}, i}-U_{\mathrm{ob}, i}$, where $U_{\mathrm{ob}, i}$ is the actual observation for a time position $t_{i}$ and $U_{\mathrm{p}, i}$ is the forecast for the same period. The statistical methods show a broader distribution of errors. This is because ARIMA and persistence fail to predict the phase of the events since they construct their predictions according to the previous observations.

The dependency of the forecasting errors on the mean wind speed of the downstream observation for all advection models is shown in Fig. 12. From there it can be inferred that the local topographic corrections are required since the $\mathrm{AH}$ model overestimates wind speeds. For the neutral periods 4 , 5,7 and 8 , the forecasting accuracy of the AHR model is higher than that of any other advection model. In those periods, introducing the orography correction results in an underestimation of the wind speed, as can be seen in the MBE of those periods. For wind speeds close to $16 \mathrm{~m} \mathrm{~s}^{-1}$ and neutral conditions, AHRO produces smaller errors (Fig. 12a). Therefore for period 2, which has a higher mean wind speed, introducing the orography correction results in a more accurate forecast than that of any other model. This is because both the roughness change correction and the orography corrections are estimated with mean neutral profiles, whose mean wind speed at the forecasting height is also close to $16 \mathrm{~m} \mathrm{~s}^{-1}$. For period 3, the one with the highest wind speed, the increasing underprediction of AHRO and AHR with wind speed results in AH predicting better than the other models.

For stable cases (periods 1, 6, 9 and 10) the performance of the advection-based models is quite similar to the performance seen in neutral cases. During periods 6 and 10, the AHR model produces smaller errors than the statistical models. Figure 13 shows the comparison of the observed and forecasted wind speeds for all models during period 6 . The figure shows that there is more scatter for the persistence and ARIMA models than for the advection models. For wind 
Table 3. RMSE, MBE and MaxAE statistics for all periods evaluated. Minimum values are indicated in bold.

\begin{tabular}{|c|c|c|c|c|c|c|c|c|c|}
\hline Period & Stability & & A & $\mathrm{AH}$ & AHR & AHRO & $\mathrm{P}$ & ARIMA & $\begin{array}{r}p, d, q \\
\text { parameters }\end{array}$ \\
\hline \multirow{3}{*}{1} & \multirow{3}{*}{ Stable } & $\operatorname{RMSE}\left(\mathrm{ms}^{-1}\right)$ & 2.69 & 1.84 & 1.26 & 0.99 & 0.49 & 0.44 & \multirow{3}{*}{$3,1,0$} \\
\hline & & $\operatorname{MBE}\left(\mathrm{ms}^{-1}\right)$ & 2.64 & 1.78 & 1.19 & 0.90 & -0.01 & -0.04 & \\
\hline & & $\operatorname{Max} A E\left(\mathrm{~ms}^{-1}\right)$ & 4.12 & 2.91 & 2.28 & 1.95 & 1.21 & 1.54 & \\
\hline \multirow{3}{*}{2} & \multirow{3}{*}{ Neutral } & $\operatorname{RMSE}\left(\mathrm{ms}^{-1}\right)$ & 2.61 & 1.29 & 0.75 & 0.71 & 1.01 & 0.93 & \multirow{3}{*}{$3,1,1$} \\
\hline & & $\operatorname{MBE}\left(\mathrm{ms}^{-1}\right)$ & 2.48 & 1.08 & 0.26 & -0.10 & -0.01 & -0.15 & \\
\hline & & $\operatorname{MaxAE}\left(\mathrm{ms}^{-1}\right)$ & 4.64 & 2.71 & 2.29 & 2.65 & 3.29 & 2.87 & \\
\hline \multirow{3}{*}{3} & \multirow{3}{*}{ Neutral } & $\operatorname{RMSE}\left(\mathrm{ms}^{-1}\right)$ & 2.16 & 0.87 & 0.91 & 1.05 & 1.10 & 0.91 & \multirow{3}{*}{$2,0,1$} \\
\hline & & $\operatorname{MBE}\left(\mathrm{ms}^{-1}\right)$ & 1.95 & 0.37 & -0.48 & -0.73 & 0.04 & 0.34 & \\
\hline & & $\operatorname{MaxAE}\left(\mathrm{ms}^{-1}\right)$ & 4.10 & 2.25 & 2.87 & 3.04 & 3.22 & 2.63 & \\
\hline \multirow{3}{*}{4} & \multirow{3}{*}{ Neutral } & $\operatorname{RMSE}\left(\mathrm{m} \mathrm{s}^{-1}\right)$ & 1.51 & 0.68 & 0.59 & 0.74 & 0.81 & 0.73 & \multirow{3}{*}{$1,0,1$} \\
\hline & & $\operatorname{MBE}\left(\mathrm{ms}^{-1}\right)$ & 1.36 & 0.37 & -0.19 & -0.49 & -0.09 & -0.29 & \\
\hline & & $\operatorname{MaxAE}\left(\mathrm{ms}^{-1}\right)$ & 2.79 & 1.49 & 1.55 & 1.83 & 2.03 & 1.75 & \\
\hline \multirow{3}{*}{5} & \multirow{3}{*}{ Neutral } & $\operatorname{RMSE}\left(\mathrm{ms}^{-1}\right)$ & 1.81 & 0.93 & 0.70 & 0.76 & 1.13 & 0.97 & \multirow{3}{*}{$1,0,0$} \\
\hline & & $\operatorname{MBE}\left(\mathrm{ms}^{-1}\right)$ & 1.56 & 0.60 & 0.01 & -0.29 & 0.05 & 0.34 & \\
\hline & & $\operatorname{MaxAE}\left(\mathrm{ms}^{-1}\right)$ & 4.42 & 3.09 & 2.41 & 2.09 & 3.21 & 2.22 & \\
\hline \multirow{3}{*}{6} & \multirow{3}{*}{ Stable } & $\operatorname{RMSE}\left(\mathrm{ms}^{-1}\right)$ & 0.78 & 0.53 & 0.52 & 0.54 & 0.70 & 0.72 & \multirow{3}{*}{$1,1,1$} \\
\hline & & $\operatorname{MBE}\left(\mathrm{ms}^{-1}\right)$ & 0.53 & 0.18 & -0.08 & -0.20 & 0.05 & 0.01 & \\
\hline & & $\operatorname{MaxAE}\left(\mathrm{ms}^{-1}\right)$ & 2.11 & 2.01 & 2.30 & 2.31 & 2.67 & 2.78 & \\
\hline \multirow{3}{*}{7} & \multirow{3}{*}{ Neutral } & $\operatorname{RMSE}\left(\mathrm{ms}^{-1}\right)$ & 2.33 & 1.15 & 0.90 & 0.97 & 1.20 & 1.16 & \multirow{3}{*}{$2,0,0$} \\
\hline & & $\operatorname{MBE}\left(\mathrm{ms}^{-1}\right)$ & 2.10 & 0.74 & -0.02 & -0.37 & 0.07 & 0.33 & \\
\hline & & $\operatorname{MaxAE}\left(\mathrm{m} \mathrm{s}^{-1}\right)$ & 5.39 & 2.95 & 3.89 & 4.23 & 3.69 & 2.92 & \\
\hline \multirow{3}{*}{8} & \multirow{3}{*}{ Neutral } & $\operatorname{RMSE}\left(\mathrm{ms}^{-1}\right)$ & 2.62 & 1.15 & 0.79 & 0.87 & 1.02 & 0.96 & \multirow{3}{*}{$2,1,1$} \\
\hline & & $\operatorname{MBE}\left(\mathrm{ms}^{-1}\right)$ & 2.45 & 0.83 & -0.03 & -0.37 & -0.02 & -0.01 & \\
\hline & & $\operatorname{MaxAE}\left(\mathrm{ms}^{-1}\right)$ & 4.54 & 2.73 & 1.98 & 2.20 & 2.95 & 2.65 & \\
\hline \multirow{3}{*}{9} & \multirow{3}{*}{ Stable } & $\operatorname{RMSE}\left(\mathrm{ms}^{-1}\right)$ & 3.01 & 2.22 & 1.62 & 1.36 & 0.43 & 0.44 & \multirow{3}{*}{$1,0,1$} \\
\hline & & $\operatorname{MBE}\left(\mathrm{ms}^{-1}\right)$ & 2.96 & 2.16 & 1.55 & 1.28 & 0.01 & 0.07 & \\
\hline & & $\operatorname{MaxAE}\left(\mathrm{ms}^{-1}\right)$ & 4.52 & 3.43 & 2.62 & 2.27 & 1.39 & 1.30 & \\
\hline \multirow{3}{*}{10} & \multirow{3}{*}{ Stable } & $\operatorname{RMSE}\left(\mathrm{ms}^{-1}\right)$ & 0.44 & 0.34 & 0.42 & 0.48 & 0.43 & 0.45 & \\
\hline & & $\operatorname{MBE}\left(\mathrm{ms}^{-1}\right)$ & 0.20 & -0.06 & -0.26 & -0.35 & 0.04 & 0.22 & $1,0,0$ \\
\hline & & $\operatorname{MaxAE}\left(\mathrm{ms}^{-1}\right)$ & 1.39 & 1.00 & 1.21 & 1.28 & 1.46 & 1.10 & \\
\hline
\end{tabular}

speeds above $8 \mathrm{~ms}^{-1}$ a high scatter between the advection models and the observations is also found.

For periods 1 and 9, all advection models show larger errors than the conventional models. This is because these periods are characterised by higher wind speeds than periods 6 and 10 . The effect of the mean wind speed in the forecasting error of stable cases is shown in Fig. 12b. Above $6 \mathrm{~m} \mathrm{~s}^{-1}$ the forecast error tends to increase with wind speed. For higher wind speeds, the forecast originates from further upstream positions and consequently higher heights. If we now look at the differences between the PPI observations at $2950 \mathrm{~m}$ and the estimation of wind speeds using Eqs. (1) and (3) from the dual-set-up observations (see Fig. 10), we can see that the differences are more pronounced at further distances. Thus, it is difficult to accurately predict the magnitude of the wind speed during stable conditions and high wind speeds, due to the increasing height in the observations at further positions, the differences in the dual-set-up and PPI observations, and the assumption of neutral stabilities during stable conditions. Although we include the shear in our advection models we are not considering the atmospheric stability.

However, in quantifying the errors for the best fitted advection model in both stable and neutral cases, the RMSE of the stable cases is in general smaller than those of the neutral periods because during stable conditions the inflow is less turbulent. For stable cases, disregarding the periods of high wind speed ( 1 and 9), the best calibrated advection 
Table 4. Improvement of all advection models over the benchmarks persistence (ImpP) and ARIMA (Imp $)$. Values corresponding to best performance are indicated in bold.

\begin{tabular}{llrr|rr|rr|rr}
\hline & & \multicolumn{3}{c|}{ A } & \multicolumn{2}{c|}{ AH } & \multicolumn{2}{c|}{ AHR } & \multicolumn{3}{c}{ AHRO } \\
\cline { 2 - 9 } Period & Stability & $\operatorname{Imp}_{\mathrm{P}}(\%)$ & $\operatorname{Imp}_{\mathrm{A}}(\%)$ & $\operatorname{Imp}_{\mathrm{P}}(\%)$ & $\operatorname{Imp}_{\mathrm{A}}(\%)$ & $\operatorname{ImpP}(\%)$ & $\operatorname{Imp}_{\mathrm{A}}(\%)$ & $\operatorname{Imp}_{\mathrm{P}}(\%)$ & $\operatorname{Imp}_{\mathrm{A}}(\%)$ \\
\hline 1 & Stable & -448.98 & -511.36 & -275.51 & -318.18 & -157.14 & -186.36 & -102.04 & -125.00 \\
2 & Neutral & -158.42 & -180.65 & -27.72 & -38.71 & 25.74 & 19.35 & $\mathbf{2 9 . 7 0}$ & $\mathbf{2 3 . 6 6}$ \\
3 & Neutral & -96.36 & -137.36 & $\mathbf{2 0 . 9 1}$ & $\mathbf{4 . 4 0}$ & 17.27 & 0.01 & 4.55 & -15.38 \\
4 & Neutral & -86.42 & -106.85 & 16.05 & 6.85 & $\mathbf{2 7 . 1 6}$ & $\mathbf{1 9 . 1 8}$ & 8.64 & -1.37 \\
5 & Neutral & -60.18 & -86.60 & 17.70 & 4.12 & $\mathbf{3 8 . 0 5}$ & $\mathbf{2 7 . 8 4}$ & 32.74 & 21.65 \\
6 & Stable & -11.43 & -8.33 & 24.29 & 26.39 & $\mathbf{2 5 . 7 1}$ & $\mathbf{2 7 . 7 8}$ & 22.86 & 25.01 \\
7 & Neutral & -94.17 & -100.86 & 4.17 & 0.86 & $\mathbf{2 5 . 0 2}$ & $\mathbf{2 2 . 4 1}$ & 19.17 & 16.38 \\
8 & Neutral & -156.86 & -172.92 & -12.75 & -19.79 & $\mathbf{2 2 . 5 5}$ & $\mathbf{1 7 . 7 1}$ & 14.71 & 9.37 \\
9 & Stable & -600.02 & -584.09 & -416.28 & -404.55 & -276.74 & -268.18 & 216.28 & -209.09 \\
10 & Stable & -2.33 & 2.22 & $\mathbf{2 0 . 9 3}$ & $\mathbf{2 4 . 4 4}$ & 2.33 & 6.67 & -11.63 & -6.67 \\
\hline
\end{tabular}
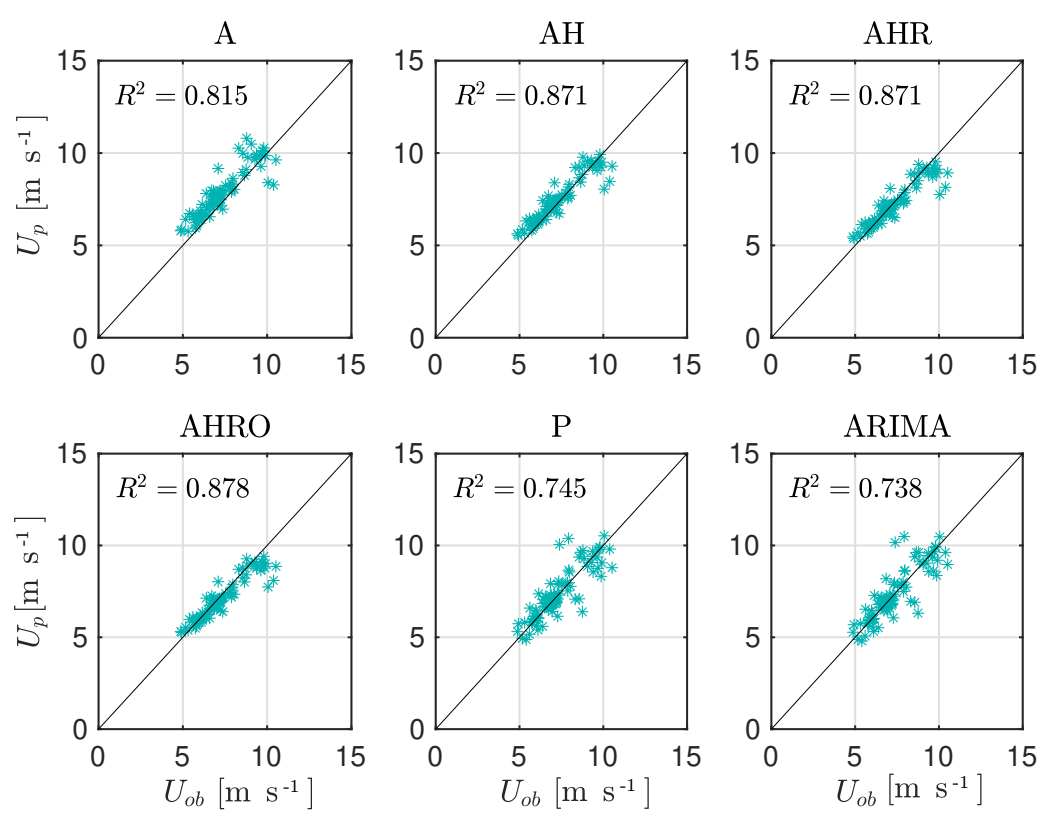

Figure 13. Comparison between the observed ob and predicted p wind speed for all evaluated models for period 6 (stable) with $N=95$.

models give improvements over persistence of $21-26 \%$ and over ARIMA of $24-28 \%$.

When looking at the forecast of wind speeds during period 7 (see Fig. 14), we can see that the advection models are able to forecast the phase of the events, but the forecast does not contain as many fluctuations as the observed wind speed at the downstream position. To analyse if this is due to the model or to the nature of the observations, the dependency of the level of fluctuations on the horizontal reconstructed wind speeds with the distance of the measurements is investigated. In Fig. 15, the ensemble average of the standard deviation of $U$, computed for every hour and elevation angle during peri- ods when all measurements are available, is displayed. The standard deviation observed by the lidar is higher closer to the coast. We attribute this to a combination of two sources: site-specific conditions and measurement artifacts. In the first source we consider the higher roughness length close to the coast, compared to positions further offshore, and the topographic effects. In the second source we include the different height in the observations for the different ranges and the different arc length used for the reconstruction of horizontal wind speeds from the lidar. Since the arc length used for the measurement increases with the distance, the reconstruction of wind speeds acts as a low-pass filter for further distances. 


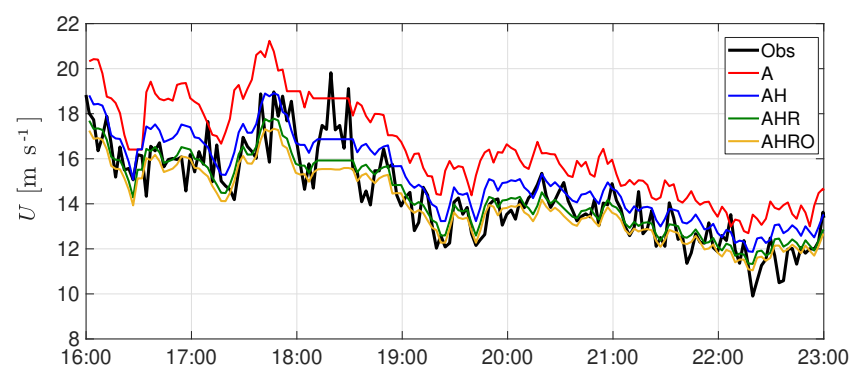

Figure 14. Time series of wind speed observations (Obs) and predictions with the A, AH, AHR and AHRO models for period 7.

This filtering effect deteriorates the prediction of the magnitude of the events, and consequently influences the maximum absolute error.

\section{Concluding remarks}

This paper evaluated the use of wind lidar observations for a very short-term forecast of near-coastal winds, using wind speed advection-based models. From our analysis on periods with neutral atmospheric conditions, the best-fitted advection-based model with corrections showed an improvement over the benchmarks persistence and ARIMA of 2138 and $4-28 \%$, respectively. Due to the different turbulent conditions experienced at every range position, the forecasting technique was not able to predict the turbulence of the fluctuations. We attribute these differences partly to the presence of the coast increasing the turbulence level as the flow approaches and the low-pass filtering inherent in the wind speed reconstruction from the lidar measurements. During stable periods, we could only produce an accurate prediction of the magnitude of the wind speed during low wind speeds. This is a reflection of the increasing difficulty of predicting winds as (i) the observation height increases at further positions, (ii) there are differences in the dual-set-up and PPI observations and (iii) neutral stability is assumed during stable conditions, due to a lack of a precise estimate of the offshore stability.

In this paper the forecasting horizon is limited to $5 \mathrm{~min}$ due to the maximum range of the lidar measurements $(6 \mathrm{~km})$ and the high wind speeds experienced during the measurement campaign. A long-range lidar system with a maximum range of $10 \mathrm{~km}$ could forecast wind speeds of up to $17 \mathrm{~m} \mathrm{~s}^{-1}$, thus generating forecasts with a horizon of $10 \mathrm{~min}$. Since commercially available ultra-range lidars can now measure up to $30 \mathrm{~km}$ (Kameyama et al., 2012), the forecasting horizon for this application could be extended up to $30 \mathrm{~min}$ ahead.

The corrections applied in our advection-based models to forecast the magnitude of the wind speed observations are necessary due to the tilted trajectories and local effects of the coastline and the cliff. However, the corrections are not perfect. The results are based on a limited number of dual-set-up

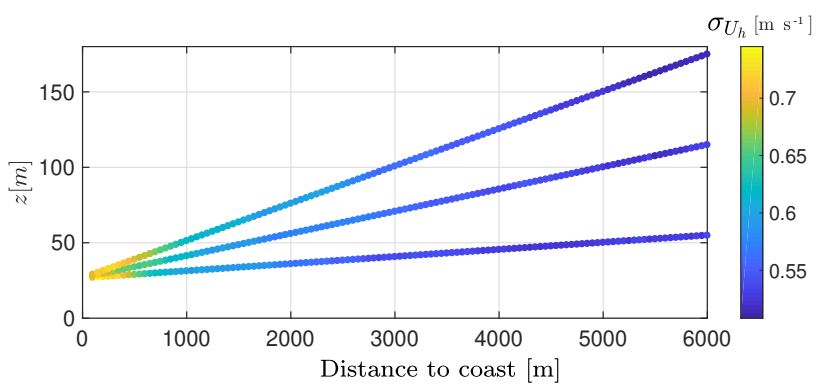

Figure 15. Ensemble average standard deviation of the horizontal wind speed with distance to shore for the three elevations' angles during all periods analysed.

measurements and it is clear that we could not find a model with a zero mean bias error. The best performing advection model depends on the wind speed and stability. Despite all these limitations, we showed that lidars (i) provide rangeresolved information to derive site-specific effects influencing the wind speed and (ii) are promising candidates for very short-term wind power applications since they can forecast wind speeds with more accuracy than the benchmarks persistence and ARIMA. To use an advection-based wind speed forecasting technique, one could better benefit from horizontal trajectories that do not require height corrections. Additionally, applying this technique in pure offshore areas improves the results since no corrections due to local effects are required. An operational lidar-based forecasting system on an offshore wind farm would need no corrections at all. Thus, it is reasonable to expect that the forecasting performance of such a system would be better than the best results we have achieved since the many corrections might not have benefited the forecasting accuracy.

Very short-term wind power forecasts typically use statistical techniques that learn from the wind speed and power data at the location of interest and surroundings. Based on our results, a long-range lidar system is likely to decrease the uncertainty in the prediction of offshore wind power, especially during ramp events, i.e. large variation in wind speed within a short period of time, for which statistical methods do not perform well.

Our analysis is a first input component to a decisionmaking model that may include spot market prices, scheduled supply and demand, and balancing costs. Thus, here it is not intended to quantify the economic impact of using a lidar-based wind speed forecast. However, as the balancing costs are proportional to the root-mean-square error, it can be assumed that they will decrease. In particular, as in most of the periods analysed the maximum absolute error is lower than that of the benchmarks, using a lidar-based wind speed forecast might have a positive impact on integrating offshore wind power into the grid. 
Further research will focus on using long-range, remotely sensed wind speed observations to predict the power produced by a single wind turbine or a wind farm.

Data availability. Lidar data can be requested from Alfredo Peña at DTU Wind Energy (aldi@dtu.dk).

Author contributions. LV conducted the research work and wrote the paper. AP and MC extensively contributed to the modelling of the coastal effects and the use of lidar observations for forecasting wind speed, respectively. LvB and MK supervised the research work and contributed to the structure of the paper. All coauthors participated in the outline and review of the paper.

Competing interests. The authors declare that they have no conflict of interest.

Acknowledgements. This project has received funding from the European Union's Horizon 2020 research and innovation programme under the Marie Skłodowska-Curie grant agreement no. 642108. Funding from the ForskEL program to the project "RUNE" no. 12263 and from the Ministry of Science and Culture of Lower Saxony to the project "ventus efficiens" (ZN3024, MWK Hannover) is acknowledged.

Edited by: Julie Lundquist

Reviewed by: two anonymous referees

\section{References}

Alexiadis, M., Dokopoulos, P., Sahsamanoglou, H., and Manousaridis, I.: Short-term forecasting of wind speed and related electrical power, Sol. Energy, 63, 61-68, https://doi.org/10.1016/S0038-092X(98)00032-2, 1998.

Barthelmie, R., Murray, F., and Pryor, S.: The economic benefit of short-term forecasting for wind energy in the UK electricity market, Energ. Policy, 36, 1687-1696, https://doi.org/10.1016/j.enpol.2008.01.027, 2008.

Beck, H. and Kühn, M.: Dynamic data filtering of long-range Doppler LiDAR wind speed measurements, Remote SensingBasel, 9, 561, https://doi.org/10.3390/rs9060561, 2017.

Box, G. E. P. and Jenkins, G. M.: Time series analysis: forecasting and control, J. Time Ser. Anal., 31, p. 303, https://doi.org/10.1111/j.1467-9892.2009.00643.x, 1976.

Cadenas, E. and Rivera, W.: Wind speed forecasting in the South Coast of Oaxaca, México, Renew. Energ., 32, 2116-2128, https://doi.org/10.1016/j.renene.2006.10.005, 2007.

Cadenas, E. and Rivera, W.: Short term wind speed forecasting in La Venta, Oaxaca, México, using artificial neural networks, Renew. Energ., 34, 274-278, https://doi.org/10.1016/j.renene.2008.03.014, 2009.

Charnock, H.: Wind stress on a water surface, Q. J. Roy. Meteor. Soc., 81, 639-640, https://doi.org/10.1002/qj.49708135027, 1955.
Damousis, I. G., Alexiadis, M. C., Theocharis, J. B., and Dokopoulos, P. S.: A fuzzy model for wind speed prediction and power generation in wind parks using spatial correlation, IEEE T. Energy Conver., 19, 352-361, https://doi.org/10.1109/Tec.2003.821865, 2004.

Danish Wind Industry Association (DWIA): Wind Energy Production as a Percentage of Total Electricity Consumtion 2005-2017, available at: http://www.windpower.org/en/knowledge/statistics/ the_danish_market.html (last access: 22 January 2018), 2018.

Dickey, D. A. and Fuller, W. A.: Distribution of the estimators for autoregressive time series with a unit root, J. Am. Stat. Assoc., 74, 427-431, https://doi.org/10.2307/2286348, 1979.

EPEXSPOT: Intraday Lead Times, available at: https: //www.epexspot.com/en/product-info/intradaycontinuous/ intraday_lead_time (last access: 25 September 2017), 2017.

Floors, R., Lea, G., Pena Diaz, A., Karagali, I., and Ahsbahs, T.: Report on RUNE's Coastal Experiment and First Inter-Comparisons Between Measurements Systems, Tech. rep., DTU Wind Energy E-0115(EN), DTU Wind Energy, Roskilde, Denmark, 2016a.

Floors, R., Peña, A., Lea, G., Vasiljević, N., Simon, E., and Courtney, M.: The RUNE Experiment - a database of remote-sensing observations of near-shore winds, Remote Sensing-Basel, 8, 884, https://doi.org/10.3390/rs8110884, 2016b.

Frehlich, R.: Scanning Doppler lidar for input into short-term wind power forecasts, J. Atmos. Ocean. Tech., 30, 230-244, https://doi.org/10.1175/JTECH-D-11-00117.1, 2013.

Geostyrelsen: available at: http://download.kortforsyningen. $\mathrm{dk} /$ content/dhm-2007overflade-16-mgrid (last access: 5 April 2017), 2016.

Giebel, G., Brownsword, R., Kariniotakis, G., Denhard, M., and Draxl, C.: The State-of-the-Art in Short-Term Prediction of Wind Power - A Literature Overview, Technical Report, EU Project ANEMOS, 109 pp., available at: http://orbit.dtu.dk/getResource? recordId=274635\&amp;objectId=1\&amp; versionId=1 (last access: 28 May 2018), 2011.

Gonzalez-Aparicio, I. and Zucker, A.: Impact of wind power uncertainty forecasting on the market integration of wind energy in Spain, Appl. Energ., 159, 334-349, https://doi.org/10.1016/j.apenergy.2015.08.104, 2015.

Hill, D. C., McMillan, D., Bell, K. R. W., and Infield, D.: Application of auto-regressive models to U.K. wind speed data for power system impact studies, IEEE T. Sustain. Energ., 3, 134141, https://doi.org/10.1109/TSTE.2011.2163324, 2012.

Holttinen, H., Meibom, P., Orths, A., Hulle, F. V., Lange, B., O'Malley, M., Pierik, J., Ummels, B., Tande, J. O., Estanqueiro, A., Gomez, E., Söder, L., Strbac, G., Shakoor, A., Ricardo, J., Smith, C., Milligan, M., and Ela, E.: Design and Operation of Power Systems with Large Amounts of Wind Power, Final Summary Report, IEA Wind Task 25, available at: https://community.ieawind.org/task25/viewdocument/ design-and-operation-of-power-syste-2?CommunityKey= 4aa82210-1b2e-43c5-b37b-1cdf11020dc8 (last access: 28 May 2018), 2016.

Høyer, J. L. and She, J.: Optimal interpolation of sea surface temperature for the North Sea and Baltic Sea, J. Marine Syst., 65, 176-189, https://doi.org/10.1016/j.jmarsys.2005.03.008, 2007.

Ibanez, E. and Milligan, M.: Impact of transmission on resource adequacy in systems with wind and solar power, 
in: IEEE Power and Energy Society General Meeting, 1-5, https://doi.org/10.1109/PESGM.2012.6343955, 2012.

Kameyama, S., Sakimura, T., Watanabe, Y., Ando, T., Asaka, K., Tanaka, H., Yanagisawa, T., Hirano, Y., and Inokuchi, H.: Wind sensing demonstration of more than $30 \mathrm{~km}$ measurable range with a $1.5 \mu \mathrm{m}$ coherent Doppler lidar which has the laser amplifier using Er,Yb:glass planar waveguide, Proc. SPIE, 8526, https://doi.org/10.1117/12.977330, 2012.

Kavasseri, R. G. and Seetharaman, K.: Day-ahead wind speed forecasting using f-ARIMA models, Renew. Energ., 34, 1388-1393, https://doi.org/10.1016/j.renene.2008.09.006, 2009.

Kraus, E. B.: Atmosphere-Ocean Interaction, Oxford University Press, New York, p. 275, 1972.

Larson, K. A. and Westrick, K.: Short-term wind forecasting using off-site observations, Wind Energy, 9, 55-62, https://doi.org/10.1002/we.179, 2006.

Li, G. and Shi, J.: On comparing three artificial neural networks for wind speed forecasting, Appl. Energ., 87, 2313-2320, https://doi.org/10.1016/j.apenergy.2009.12.013, 2010.

Mikkelsen, T., Angelou, N., Hansen, K., Sjöholm, M., Harris, M., Slinger, C., Hadley, P., Scullion, R., Ellis, G., and Vives, G.: A spinner-integrated wind lidar for enhanced wind turbine control, Wind Energy, 16, 625-643, https://doi.org/10.1002/we.1564, 2013.

Monfared, M., Rastegar, H., and Kojabadi, H. M.: A new strategy for wind speed forecasting using artificial intelligent methods, Renew. Energ., 34, 845-848, https://doi.org/10.1016/j.renene.2008.04.017, 2009.

Peña, A., Floors, R., Sathe, A., Gryning, S. E., Wagner, R., Courtney, M. S., Larsén, X. G., Hahmann, A. N., and Hasager, C. B.: Ten years of boundary-layer and wind-power meteorology at Høvsøre, Denmark, Bound.-Lay. Meteorol., 158, 1-26, https://doi.org/10.1007/s10546-015-0079-8, 2016.

Peña, A., Mann, J., and Dimitrov, N.: Turbulence characterization from a forward-looking nacelle lidar, Wind Energ. Sci., 2, 133152, https://doi.org/10.5194/wes-2-133-2017, 2017.

Sanchez, R. and Rørbæk, K.: Metocean Buoy Deployment, Technical Report, DHI, 2016.
Schlueter, R. A., Sigari, G., and Costi, A.: Wind array power prediction for improved operating economics and reliability, IEEE T. Power Syst., 1, 137-142, https://doi.org/10.1109/TPWRS.1986.4334859, 1986.

Simon, E. and Courtney, M.: A Comparison of Sector-Scan and Dual Doppler Wind Measurements at Høvsøre Test Station - One Lidar or Two?, Tech. rep., DTU Wind Energy E-0112(EN), DTU Wind Energy, Roskilde, Denmark, 2016.

Smith, S. D.: Wind stress and heat flux over the ocean in gale force winds, J. Phys. Oceanogr., 10, 709-726, https://doi.org/10.1175/15200485(1980)010<0709:WSAHFO>2.0.CO;2, 1980.

Stawiarski, C., Träumner, K., Knigge, C., and Calhoun, R.: Scopes and challenges of dual-Doppler lidar wind measurements An Error Analysis, J. Atmos. Ocean. Tech., 30, 2044-2062, https://doi.org/10.1175/JTECH-D-12-00244.1, 2013.

Taylor, G. I.: The spectrum of turbulence, P. Roy Soc. A-Math. Phy., 164, 476-490, https://doi.org/10.1098/rspa.1938.0032, 1938.

Torres, J. L., Garcia, A., De Blas, M., and De Francisco, A.: Forecast of hourly average wind speed with ARMA models in Navarre (Spain), Sol. Energy, 79, 65-77, https://doi.org/10.1016/j.solener.2004.09.013, 2005.

Troen, I. and Lundtang Petersen, E.: European Wind Atlas, Ris $\emptyset$ National Laboratory, Roskilde, p. 656, 1989.

Wang, Q., Martinez-Anido, C. B., Wu, H., Florita, A. R., and Hodge, B. M.: Quantifying the economic and grid reliability impacts of improved wind power forecasting, IEEE T. Sustain. Energ., 7, 1525-1537, https://doi.org/10.1109/TSTE.2016.2560628, 2016.

Wharton, S., Newman, J., Qualley, G., and Miller, W.: Measuring turbine inflow with vertically-profiling lidar in complex terrain, J. Wind Eng. Ind. Aerod., 142, 217-231, https://doi.org/10.1016/j.jweia.2015.03.023, 2015. 